\title{
The Influence of Measurement Methodology on the Accuracy of Electrical Waveform Distortion Analysis
}

\author{
Jacek Bartman, Bogdan Kwiatkowski \\ Department of Computer Engineering, Faculty of Mathematics and Natural Sciences, University of Rzeszow, \\ 35-959 Rzeszow,Poland,jbartman@ur.edu.pl
}

\begin{abstract}
The present paper covers a review of documents that specify measurement methods of voltage waveform distortion. It also presents measurement stages of waveform components that are uncommon in the classic fundamentals of electrotechnics and signal theory, including the creation process of groups and subgroups of harmonics and interharmonics. Moreover, the paper discusses selected distortion factors of periodic waveforms and presents analyses that compare the values of these distortion indices. The measurements were carried out in the cycle per cycle mode and the measurement methodology that was used complies with the IEC 61000-4-7 norm. The studies showed significant discrepancies between the values of analyzed parameters.
\end{abstract}

Keywords: Distortion measurement, harmonic analysis, inverters, IEC standards, factors of waveforms distortion.

\section{INTRODUCTION}

Distorted waveforms are the signals with non-sinusoidal time dependence. As far as electrical voltage and current are concerned, distorted waveforms are the results of the use of non-linear electrical energy loads [1]-[4]. Until they were a minor group among electrical energy loads, their work has had little impact. However, their amount is constantly growing, as well as their influence on the shape of voltage and current waveforms. Consequently, the issue of distorted waveform measurements and analyses is becoming more significant.

Periodical waveforms are very often involved when voltage and current waveforms are distorted as a result of non-linear machine work. However, when waveform distortion is the result of the work of electrical switching components, the signal is very often unsteady [5], [6] and has components of frequency from several hundreds of $\mathrm{Hz}$ to several tens of $\mathrm{kHz}$, that are not synchronized with the network. This type of signals is not easy to measure and analyze as they comprise both harmonics and interharmonics, slow changing components and fast changing components that additionally can change over time. Such waveform raises two problems:

- minimum number of samples, that guarantees the reflection of fast changing and slow changing components included in distortion, can be very high,

- fundamental Fourier frequency cannot be determined as the frequency of all components is unknown [7].

Modern power quality analyzers have enough memory and are able to sample with such high frequencies, that the problem mentioned as first can be perceived as burdensome because of increased measurement and calculation costs. The second problem, as far as interharmonics are concerned, fails to allow finding the exact fundamental Fourier frequency. However, there are many (parametric and nonparametric) methods for digital parameter estimation of the fundamental component that allow determining its frequency with acceptable accuracy. Most commonly chosen methods use the spectral analysis [5], [7], [8].

The norms IEC 61000-4-30 [9] and IEC 61000-4-7 [10] are the documents that specify methods of studies and measurements of power quality, including distortions of current and voltage.

The analyses presented in the current paper compare the values given above, for various frequencies of the output of a frequency inverter. They were conducted on the basis of measurements that comply with the norm [10] and made in the cycle per cycle mode

\section{MEASUREMENTS STANDARDIZATION}

Measurement methodology and requirements for devices used in power quality testing, including current and voltage distortions, were included in the norms IEC 61000-4-30 [9] and IEC 61000-4-7 [10]. There are many references [11], [12] that clarify recommendations or suggestions related to the waveform distortion analysis included in the norms mentioned above.

According to the recommendations of the norms, the frequency analysis of waveforms should include 50 
harmonics determined by the DFT method. The width of the time window of the DFT analysis is determined as $200 \mathrm{~ms}(10$ periods $50 \mathrm{~Hz}$ ), and frequency resolution is $5 \mathrm{~Hz}$. The norm recommends to conduct averaging of selected values in a very short (3 s), short (10 min), and long (2 h) measurement time. Basic measurement of interharmonics should be carried out for 10-period non-overlapping centered subgroups of interharmonics.

In order to determine quantitative waveform distortion, the IEC 61000-4-7 [10] introduces the conception of grouping. It says that the spectrum with $5 \mathrm{~Hz}$ frequency obtained as a result of DFT is subject to grouping. The norm defines: a group of harmonics, a subgroup of harmonic, a group of interharmonics, and a subgroup of interharmonics. Assumed by the norm notations:

$Y_{g, h} \quad$ - effective value of a group of $h$-th harmonic,

$Y_{s g, h}$ - effective value of a subgroup of $h$ - $t h$ harmonic,

$Y_{i g, h} \quad$ - effective value of a group of interharmonics that are $h$-th and $(h+1)$ harmonic,

$Y_{C,(N \bullet h)+k}$ - effective value of spectrum component, that corresponds to an initial bar of DFT of $(N \bullet h)+k$, row,

$N$ - number of periods of fundamental harmonic in a measurement window,

the groups and subgroups mentioned before can be defined.

A) According to the norm, the value of a group of h-th harmonic is determined on the basis of h-th harmonic and of ten neighboring interharmonics. However, only 8 closest values and half of values of the furthest neighbors (Fig.1.):

$$
\mathrm{Y}_{\mathrm{g}, \mathrm{h}}^{2}=\sum_{k=-(N / 2-1)}^{(N / 2)-1} Y_{C,(\mathrm{~N} \bullet \mathrm{h})+\mathrm{k}}^{2}+\frac{Y_{C,(\mathrm{~N} \bullet \mathrm{h})-\mathrm{N} / 2}^{2}+Y_{C,(\mathrm{~N} \bullet \mathrm{h})+\mathrm{N} / 2}^{2}}{2}
$$

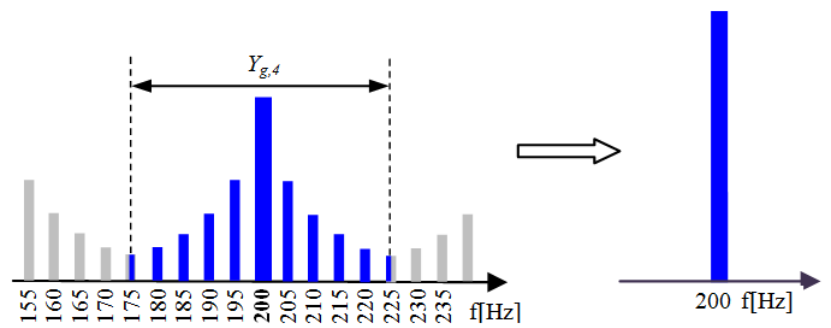

Fig.1. The idea of creating a harmonic group.

B) The value of a subgroup of $h$-th harmonic is determined on the basis of $\mathrm{h}$-th harmonic and two neighboring interharmonics (Fig.2.):

$$
\mathrm{Y}_{\mathrm{sg}, \mathrm{h}}^{2}=\sum_{k=-1}^{1} Y_{C,(\mathrm{~N} \bullet \mathrm{h})+\mathrm{k}}^{2}
$$

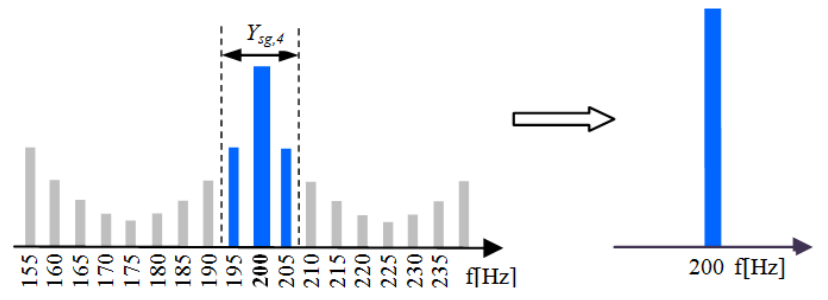

Fig.2. The idea of creating a harmonic subgroup.
C) In order to determine a group of interharmonics that are between h-th and $(h+1)$ harmonic, all bars of a transform that are between the harmonics should be included (Fig.3.):

$$
\mathrm{Y}_{\mathrm{ig}, \mathrm{h}}^{2}=\sum_{k=1}^{N-1} Y_{C,(\mathrm{~N} \bullet \mathrm{h})+\mathrm{k}}^{2}
$$

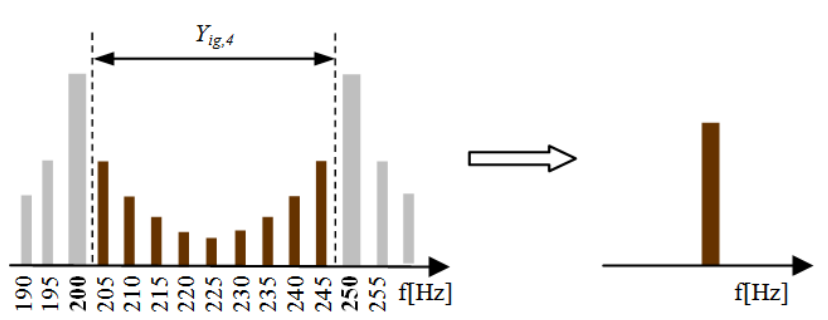

Fig.3. The idea of creating an interharmonic group.

D) In order to determine the value of an interharmonic group, the components that are direct neighbors with harmonic frequencies should be excluded from dependence (3) (Fig.4.):

$$
\mathrm{Y}_{\mathrm{isg}, \mathrm{h}}^{2}=\sum_{k=2}^{N-2} Y_{C,(\mathrm{~N} \bullet \mathrm{h})+\mathrm{k}}^{2}
$$

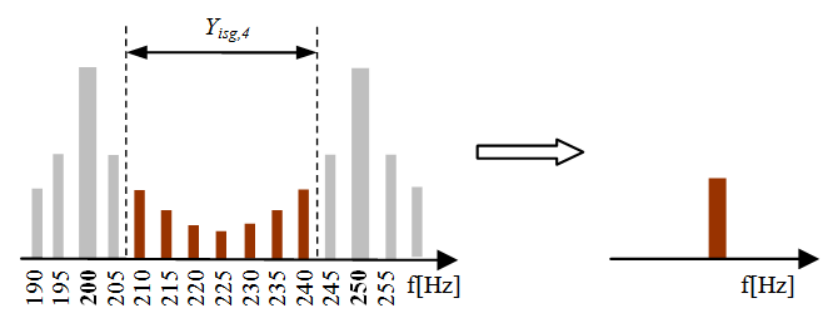

Fig.4. The idea of creating an interharmonic subgroup.

\section{EVALUATION OF WAVEFORM DISTORTION}

In order to evaluate distortion of a periodical waveform, it is necessary to determine indices which would enable to make the evaluation more objective according to the assumed criteria. Distortion analysis is very often begun with spectrum analysis conducted based on Discrete Fourier Transform DFT [5], [7], [8], [13]-[18]. According to DFT, the analyzed waveform $y(t)$ with a period $T$ must meet the following conditions of Dirichlet:

- be absolutely integrable, that is:

$$
\int_{o}^{T}|y(t)| d t<\infty
$$

- have a finite number of local extremes within one period,

- have a finite number of discontinuity points first kind, within one period.

In order to properly conduct DFT, it is necessary to select an appropriate sampling period and determine the period of a fundamental component (of minimum width of measurement window) [7], [16], [19]. The width of a measurement window 
must be the absolute multiplicity of a period of analyzed waveform and on the accuracy of its determination depends the transform's accuracy. This is not an easy task as far as distorted waveforms that have both harmonics and interharmonics are concerned [5]-[8]. The relevance of this question found reflection in many papers, and many algorithms were created in order to precisely estimate a waveform period [5], [15], [17], [18], [20]. In fact, however, unstable frequency in a waveform makes it impossible to precisely determine a fundamental frequency. As a result, a determined DFT transform is not accurate [15], [16]. However, despite its weaknesses and imperfections, and despite the fact that there are many other methods, DFT is still the most commonly applied method of the distorted waveform analysis. It results from its simplicity and easy implementation.

\section{FACTORS OF WAVEFORMS DISTORTION}

Various indices that carry different information can be used for the evaluation of waveform distortion. The current paper aims at finding out whether and how measurement methodology influences their results. Thus, the most popular indices used for the evaluation of waveform distortion were selected. The indices used in the paper are compared below:

\section{A. Effective value}

The effective value of a periodical waveform is presented with the dependence:

$$
X_{R M S}=\sqrt{\frac{1}{T} \int_{t_{0}}^{t_{0}+T} f^{2}(t)} d t=\sqrt{\sum_{k=1}^{\infty} X_{k}^{2}} \approx \sqrt{\sum_{k=1}^{N} X_{k}^{2}}
$$

In case of current, effective value is described by the value of direct current which flowing through an ideal resistance, being all the time the multiple of a period, causes releasing of energy the same as alternating current simultaneously flowing through.

\section{B. K-th harmonic content factor}

The factor of harmonic content determines the contribution of particular components to a signal waveform

$$
w_{k}=\frac{x_{(k)}}{x_{(1)}} \cdot 100 \%
$$

\section{K-th interharmonic content factor}

The factor of interharmonic content determines the contribution of particular interharmonics to a signal waveform.

$$
w_{k}=\frac{v_{(k)}}{x_{(1)}} \cdot 100 \%
$$

\section{Total Harmonic Distortion}

The THD factor reflects the relation of higher harmonic effective value to a fundamental component effective value:

$$
T H D=\frac{\sqrt{\sum_{k=2}^{N} X_{k}^{2}}}{X_{(1)}}
$$

There are also definitions that define the THD factor as the relation of higher harmonic effective value to a signal effective value. In the paper [21] the author showed that the factor determined by dependence (9) is more useful and unambiguous. Most power analyzers set the value of a THD factor using this dependence, and the analyzer used for the studies described below uses this definition.

\section{E. Crest factor}

Crest factor is used for determining the degree of waveform distortion and is defined as the relation of crest value to effective value:

$$
C F=\frac{\max |f(t)|}{X_{R M S}}
$$

where: $f(t)$ - signal time waveform,

$X_{(k)}$ - k-th harmonic of signal spectrum,

$V_{(k)}$ - k-th interharmonic of signal spectrum,

$X_{R M S}$ - effective value.

In order to gain the accurate assessment of the electrical waveform distortion, the distortion components have to be representative and integral to reality. The authors of numerous works [6], [8], [23], [24], [25], [26] indicate that restriction of the spectrum suggested in the norm [10] to 50 components may be the reason for the discrepancies. In work [23] presents the practical example of the supply voltage on a ship. In the voltage, apart from the fundamental component, there are dominating components with the frequency above $25,000 \mathrm{~Hz}$. In this case the analysis of the waveform distortion requires indicating harmonics with frequencies higher than the frequency of 50 harmonic. The author proves that the THD component, after extending the rage of considered harmonics, increases from $1.51 \%$ to $7.9 \%$. In other works comprising similar issues [24] it was claimed that to monitor the electrical waveform distortion on a ship, it is advisable to apply the THD components which comprise the components with frequencies up to $10 \mathrm{kHz}$.

The impact of the number of harmonics on the value of the THD component is presented also in the work of [25]. The authors observed that the value of the component calculated to the frequency higher than the frequency switching of the semiconductors' elements of the converter, varies from the value gained according to the IEC standards. That is why the authors claim that a complete harmonic distortion has to be calculated to harmonics higher than the frequency of the converter switch and not to restrict the experiment only to 50 components. 
On the contrary, the paper [8] presents the comparison of an original signal with the signal obtained on the basis of the spectrum determined according to the norm [10] - the difference between the recreated signal and the original signal was significant. It was probably caused, among others, by a reduced range of analyzed spectrum, according to the norm [10]. Further studies [6], [26] indicated that narrowing the spectrum of harmonics may affect other parameters that describe electrical waveforms such as effective value (RMS), waveform distortion factor (THD), and crest factor (CF).

\section{TESTING STATION}

The studies were conducted at a well-prepared measuring stand that comprised the following elements: Emerson Commander SK frequency inverter, $1.5 \mathrm{~kW}$ Temal 3Sg90L4-IE2 induction motor, $1.5 \mathrm{~kW}$ Delta ECMA-E21315GS servomotor, Elspec Blackbox G4500power quality analyzer, MS SQL database server, Microcomputer with PQScada and PQInvestigator softwares dedicated to Elspec Blackbox G4500 analyzer.

While running, a frequency inverter supplies an induction motor. It enables to adjust the frequency of its speed. The motor is loaded with a servomotor mounted on the same bed. Class A Elspec Blackbox G4500 analyzer is responsible for measurements. It has 11 measurement channels that enable simultaneous measurement of voltage and current in each phase. Voltage sampling frequency enables the analysis of up to 511 harmonic components, and in case of current, up to 127 components. Moreover, the device enables the analysis of interharmonics. The analyzer enables simultaneous recording of power quality data according to the norm IEC 61000-4-30 and in the cycle per cycle mode. It is possible thanks to two simultaneously running conversion motors realizing FFT of each cycle for both methods and for all channels.

PQScada software enables to send measurement data from analyzer to the MS-SQL server. Properly configured PQInvestigator application acquires data from the MS-SQL server and enables to conduct analyses and their visualization.

\section{RESULtS}

Measurements were made at the testing station as described in the previous section of the paper. The values of factors were mentioned in section 3 for various frequencies of a fundamental component, setting various values of frequency of motor supplied voltage $(38.1 \mathrm{~Hz} ; 42.5 \mathrm{~Hz}$; $45.8 \mathrm{~Hz} ; 49.7 \mathrm{~Hz} ; 53.7 \mathrm{~Hz} ; 57.6 \mathrm{~Hz} ; 61.6 \mathrm{~Hz}$ ) and using the analyzer's ability to simultaneous data recording in the cycle per cycle mode (CpC). According to the norm IEC 61000-430 (IEC), the values of the factors mentioned in point 3 were compared for various frequencies of a fundamental component.

Fig.5. shows analyzed voltage waveforms which have large distortions. Such comparison shows that reducing the voltage frequency below $50 \mathrm{~Hz}(45.8 \mathrm{~Hz}, 42.5 \mathrm{~Hz})$ causes an increasingly fuzzy waveform. It does not occur while raising the frequency above $50 \mathrm{~Hz}$.

The shape of voltage waveforms (Fig.5.) indicates that it comprises many components. Thus, a wide spectrum of harmonics and possibly interharmonics should be expected. Another figure (Fig.6.) presents the initial voltage spectrum for various frequencies related to the fundamental component, and the spectrum of interharmonics expressed in volts. The spectra shown in the first (IEC) column of Fig. 6. were recorded in accordance with the norm IEC 61000-4-30 [9]. Their observation leads to the conclusion that distortions of voltage waveform are caused mainly by the third harmonic.

This conclusion is erroneous as in the full spectrum of harmonics, a great contribution of higher components can be observed (second column, Fig.6.). In case of frequencies lower than $50 \mathrm{~Hz}$, a few groups of very high harmonics appear. This justifies the fuzzy time waveforms exactly for these frequencies. The analysis of interharmonics (third column, Fig.6.) indicates that they influence the shape of waveforms, but it is definitely bigger for frequencies above $50 \mathrm{~Hz}$.

The THD factor is a secondary value in regard to the content of particular harmonics However, it reflects global influence of higher harmonics on the shape of waveforms.
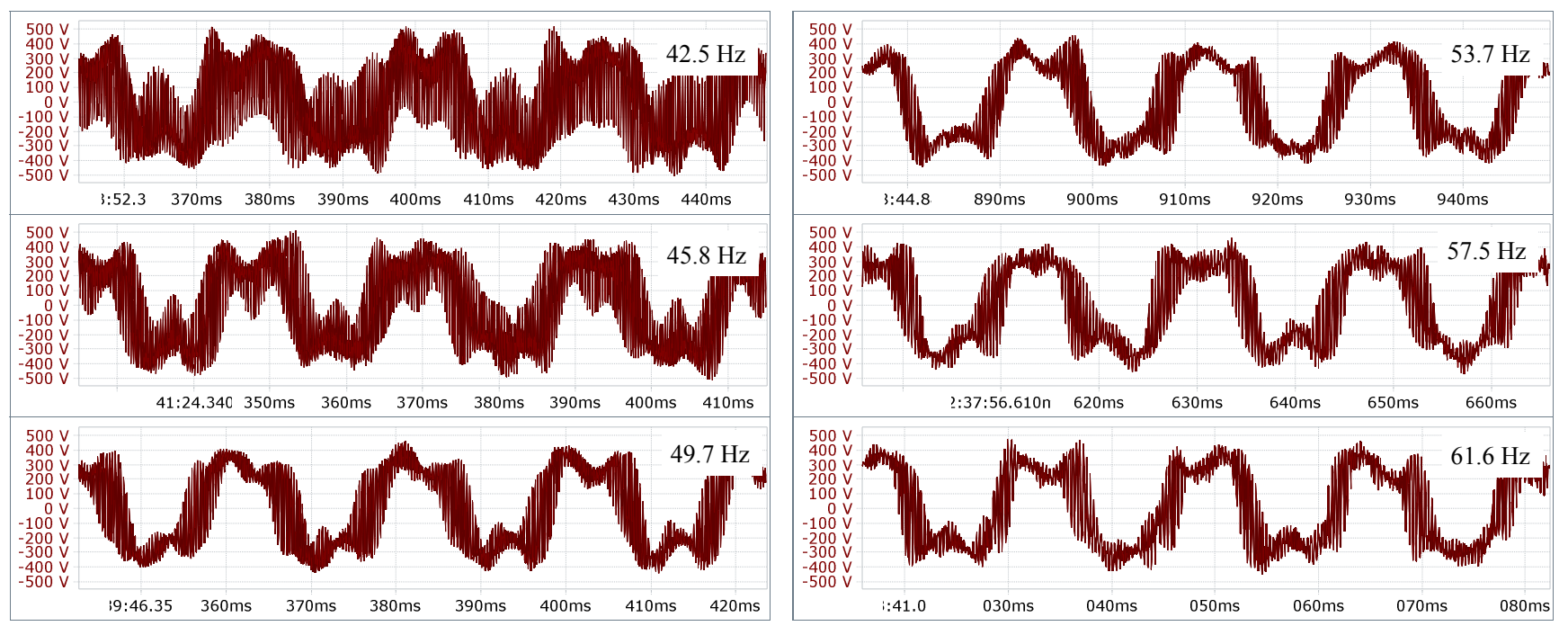

Fig.5. Voltage waveforms for various powering frequencies. 


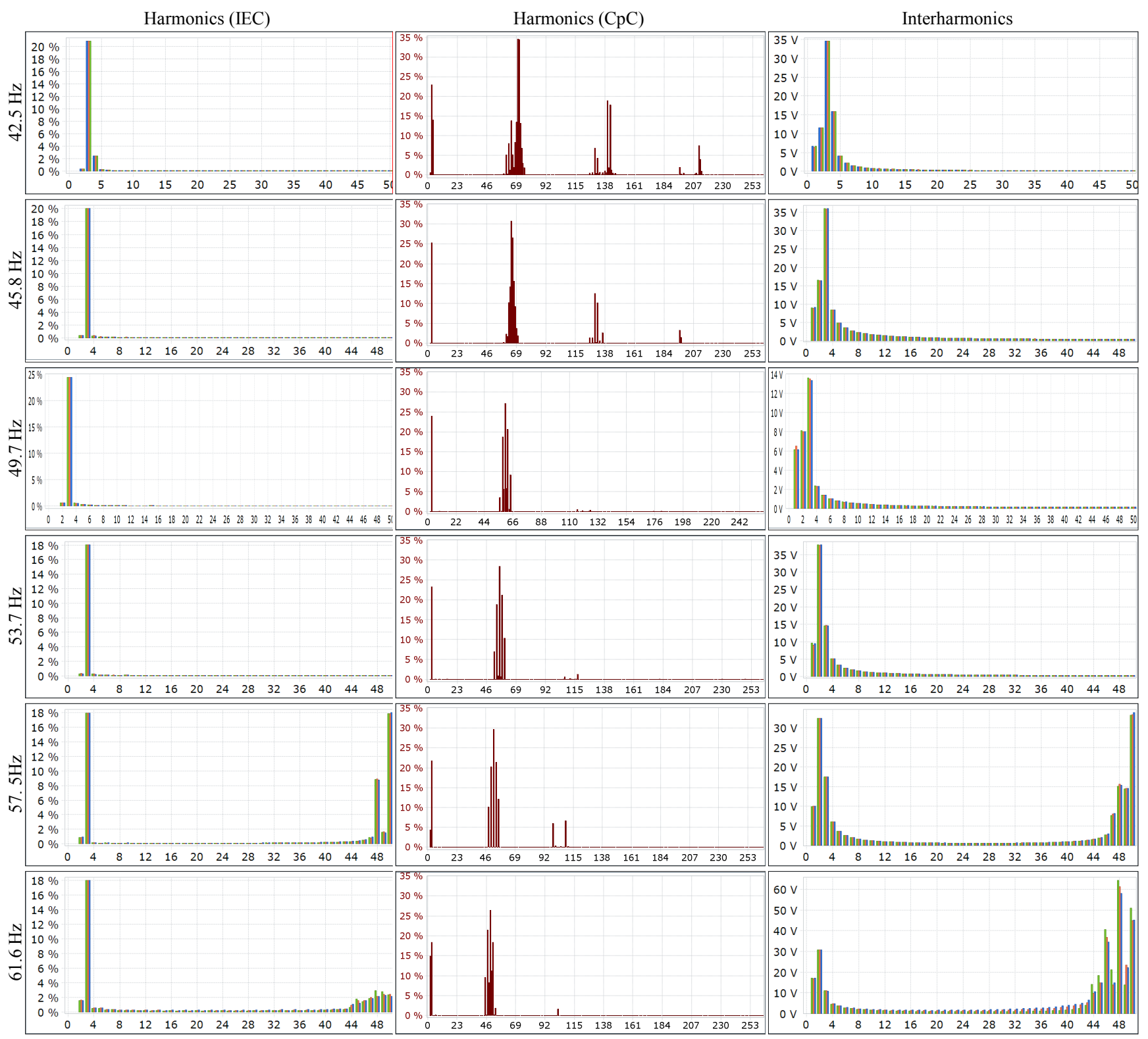

Fig.6. Spectra of harmonics and interharmonics recorded for various voltage frequencies during measurements in the cycle per cycle mode $(\mathrm{CpC})$ and in accordance with the norm [9].

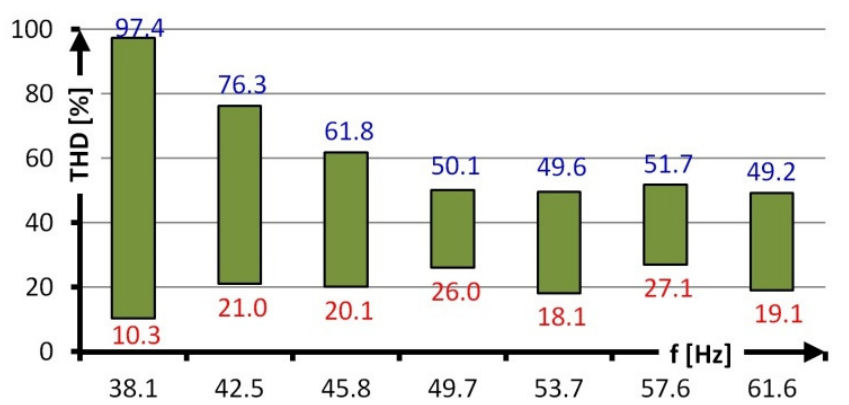

Fig.7. Differences between average values of THD recorded during measurements in the cycle per cycle mode $(\mathrm{CpC})$ and in accordance with the norm [9].
Fig.7. and Fig.8. show a dependence between measurement IEC 61000-4-30 [9] indicating a significantly lower value of THD results of the factor and the assumed methodology. The measurements taken according to the recommendations of the IEC 61000-4-30 [9] norm, show significantly smaller value of the THD factor than the measurements taken cycle after cycle. Analyzing the relation (9) and Fig.7. it can be easily observed that it is caused by not taking into account the harmonics higher than 50 in measurements consistent with the norm. The measurements conducted according to the recommendation of the norm IEC 61000-4-30 [9] indicate that both the value and the changes in THD are small, although they are large according to the cycle per cycle measurements (Fig.8.). 


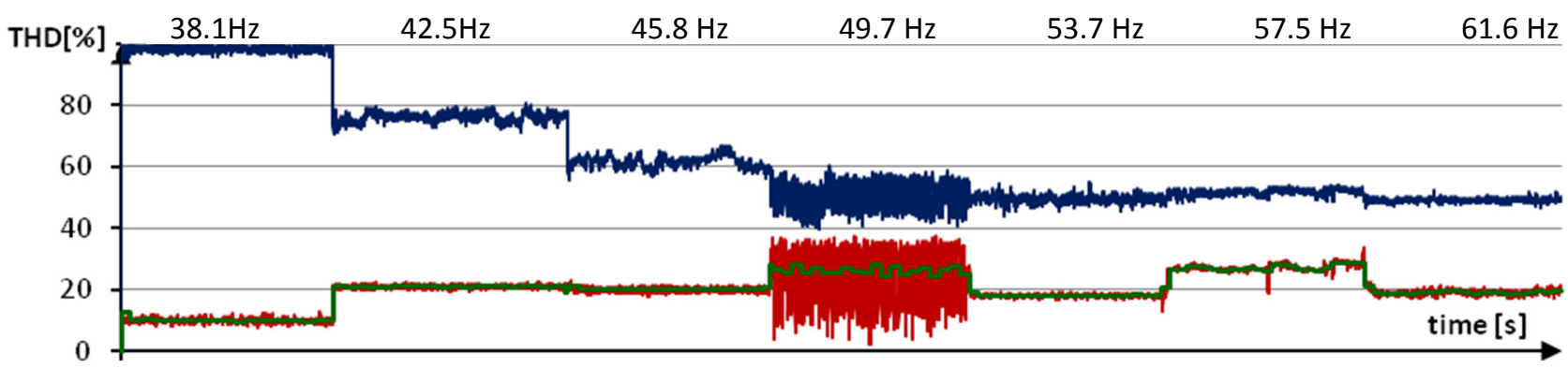

Fig.8. Changes in THD recorded for various voltage frequencies during cycle per cycle measurements $(\mathrm{CpC})$ and in accordance with the norm [9]. Dark blue line - cycle per cycle, red line - analysis in the window with 10 periods, green line - averaged value in the time of 150 periods.

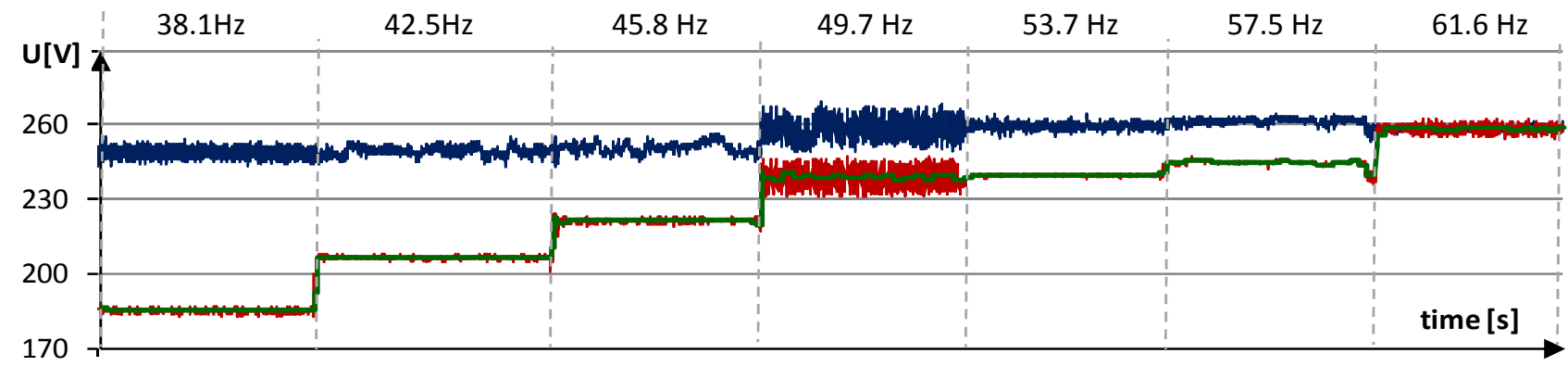

Fig.9. Changes in RMS recorded for various voltage frequencies during cycle per cycle measurements (CpC) and in accordance with the norm [9]. Dark blue line - cycle per cycle including all components, red line - analysis in the window of 10 periods, green line - averaged value in the time of 150 periods.

The measurements of voltage effective value also show great discrepancy between the values measured cycle per cycle and the values measured according to the norm IEC 61000-4-30 (Fig.9.). Similarly to the measurements of THD, the values measured according to the norm are lower than the values measured in the cycle per cycle mode. Discrepancy between the measurements decreases with an increase in frequency of the measured voltage (Fig.10.).

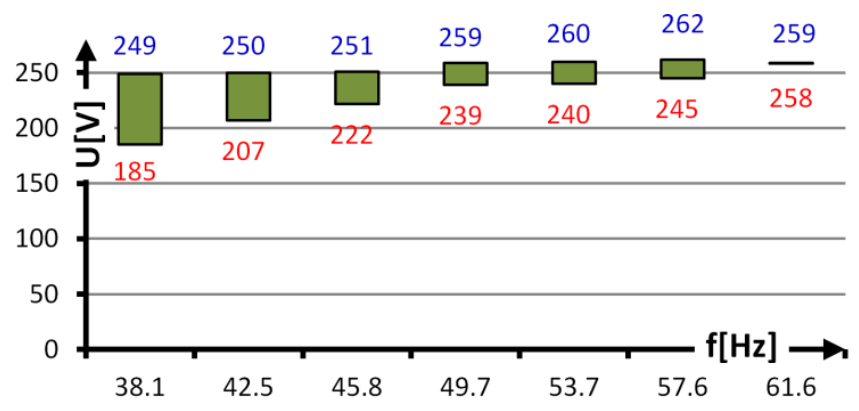

Fig.10. Differences between average values of RMS recorded during cycle per cycle measurements $(\mathrm{CpC})$ and in accordance with the norm IEC 61000-4-30.

Another study compared values of the crest factor set from cycle per cycle measurements and in accordance with the norm [9] (Fig.11.). Similarly, as in the case of THD and RMS, the set values differed. Moreover, the measurements from particular periods taken cycle per cycle were significantly different.

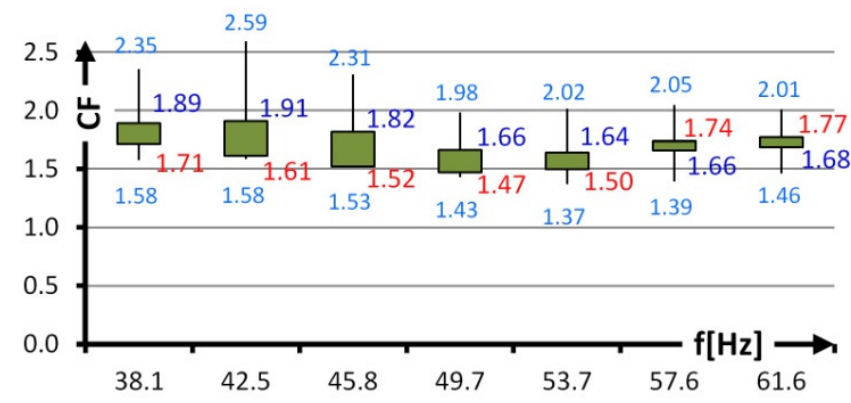

Fig.11. Differences between average values of crest factor recorded during cycle per cycle $(\mathrm{CpC})$ and in accordance with the norm IEC 61000-4-30. Blue color describes minimum and maximum values measured in the $\mathrm{CpC}$.

\section{CONCLUSIONS}

The paper includes the review of documents that specify measurement methods of voltage waveform distortion. It presents measurement stages of waveform components uncommon in the classic fundamentals of electrotechnics and signal theory, including the creation process of groups and subgroups of harmonics and interharmonics. Moreover, selected distortion indices of distorted waveforms were presented.

The evaluation of voltage and current waveform distortion is crucial as far as the analysis of power quality is concerned. Thus, it should be unambiguous and accurate. Most devices available in the market enable accurate measurements and analyses of mains electricity, according to the norms [9], [10]. 
The studies presented in the paper showed that using analyzers, which work according to the norms, for measuring highly distorted signals, may result in errors.

The measurement methodology, however, may lead to erroneous results caused by restrictions of spectrum (in accordance with the norms [9], [10]).

\section{REFERENCES}

[1] Shmilovitz, D. (2005). On the definition of total harmonic distortion and its effect on measurement interpretation. IEEE Transactions on Power Delivery, 20 (1), 526-528.

[2] Binkowski, T. (2016). Influence of current sampling frequency on voltage source inverter fuzzy correction. In 13th Selected Issues of Electrical Engineering and Electronics (WZEE). IEEE.

[3] Kamuda, K., Klepacki, D., Kuryło, K. Sabat, W. (2015). Statistical analysis of influence of the low-power nonlinear loads on deformation of supply voltage. Przeglad Elektrotechniczny, 91 (8), 19-22. (in Polish)

[4] Sobczynski, D. (2015). A concept of a power electronic converter for a BLDC motor drive system in aviation. Aviation, 19 (1), 36-39.

[5] Rezmer, J., Leonowicz, Z., Gono, R. (2011). Analysis of distorted waveform in power converter systems. Przeglą Elektrotechniczny, 87 (1), 254-257.

[6] Bartman, J. (2017). The analysis of output voltage distortion of inverter for frequency lower than the nominal. Journal of Electrical Engineering, 68 (3), 194-199.

[7] Hanzelka, Z., Bień, A. (2004). Harmonics. Interharmonics. Power Quality Application Guide 3.1.1., Copper Development Association.

[8] Bartman, J. (2016). Accuracy of reflecting the waveforms of current and voltage through their spectrum determined by the standards regulating measurements. Revue Roumaine des Sciences Techniques - Serie Électrotechnique et Énergétique, 61 (4), 355-360.

[9] International Electrotechnical Commission. (2015). Electromagnetic compatibility (EMC) - Part 4-30: Testing and measurement techniques - Power quality measurement methods. IEC 61000-4-30: 2015 RLV.

[10] International Electrotechnical Commission. (2002). Electromagnetic compatibility (EMC) - Part 4-7: Testing and measurement techniques - General guide on harmonics and interharmonics measurements and instrumentation, for power supply systems and equipment connected thereto. IEC 61000-4-7: 2002(E).

[11] Bollen, M., Olofsson, M., Larsson, A., Ronnberg, S., Lundmark, M. (2014). Standards for supraharmonics (2 to $150 \mathrm{kHz}$ ). IEEE Electromagnetic Compatibility Magazine, 3 (1), 114-119.

[12] Leszczyński, J. (2010). Research on the quality of electricity: A comparative analysis of methods and regulations. Prace Naukowe: Instytutu Maszyn, Napędów i Pomiarów Elektrycznych Politechniki
Wrocławskiej: Studia i Materiaty, 30, 520-534. (in Polish)

[13] Bartman, J., Koziorowska, A., Kuryło, K., Malska, W. (2011). Analysis of the real electric parameters feed water-pump drive systems. Przeglad Elektrotechniczny, 87 (8), 8-11. (in Polish)

[14] Koziorowska, A., Bartman, J. (2014). The influence of reactive power compensation on the content of higher harmonics in the voltage and current waveforms. Przeglad Elektrotechniczny, 90 (1), 136-140.

[15] Lin, W. (2012). Current harmonics and interharmonics measurement using Recursive Group-Harmonic Current Minimizing Algorithm. IEEE Transactions on Industrial Electronics, 59 (2), 1184-1193.

[16] Pawłowski, M. (2010). Basics of harmonic analysis of distorted currents and voltages in power supply networks. Mechanizacja i Automatyzacja Górnictwa, 7, 17-23. (in Polish)

[17] Petrović, P. (2012). Frequency and parameter estimation of multi-sinusoidal signal. Measurement Science Review, 12 (5), 175-183.

[18] Knežević, J.M., Katić, V.A. (2011). The hybrid method for on-line harmonic analysis. Advances in Electrical and Computer Engineering, 11 (3), 29-34.

[19] Chapman, D. (2001). Harmonics: Causes and effects. Power Quality Application Guide 3.1., Copper Development Association.

[20] Antić, B.M., Mitrović, Z.L., Vujičić, V.V. (2012), A method for harmonic measurement of real power grid signals with frequency drift using instruments with internally generated reference frequency. Measurement Science Review, 12 (6), 277-285.

[21] Shmilovitz, D., Duan, J., Czarkowski, D., Zabar, Z., Lee, S. (2007). Characteristics of modern nonlinear loads and their influence on systems with distributed generation. International Journal Energy Technology and Policy, 5 (2), 219-240.

[22] Koziorowska, A. Bartman, J. (2012), A-model as a way of squirrel cage induction motor modelling used in pumps drive systems. International Journal of Numerical Modelling, 25, 103-114.

[23] Mindykowski, J. (2016). Case study based overview of some contemporary challenges to power quality in ship systems. Inventions, 1 (2), 12.

[24] Tarasiuk, T., Mindykowski, J. (2015). Problem of power quality in the wake of ship technology development. Ocean Engineering, 107, 108-117.

[25] Kus, V., Josefova, T. (2017). Study of the input current harmonic distortion of voltage-source active. Revue Roumaine des Sciences Techniques - Serie Électrotechnique et Énergétique, 62 (2), 185-191.

[26] Bartman, J. (2018). Evaluating the level of waveform distortion. In Analysis and Simulation of Electrical and Computer Systems. Springer, 305-318.

Received September 30, 2017. Accepted March 20, 2018. 